\title{
El startup como factor fundamental en el cambio económico de la Parroquia San Andrés de la Provincia de Chimborazo
}

The startup as a fundamental factor in the economic change of the San Andrés Parish of the Province of Chimborazo

Carlos Iván Villalva Heredia. ${ }^{1}$, Ligia Maricela Niama Rivera. ${ }^{2}$, Mónica Paulina Terán Pérez. ${ }^{3}$ \& Byron Santiago Once Collaguazo. ${ }^{4}$

\section{Recibido: 22-06-2020 /Aceptado: 20-07-2020 / Publicado: 07-08-2020}

\begin{abstract}
.
DOI: https://doi.org/10.33262/concienciadigital.v3i3.1.1370

In Ecuador and specifically in the different parishes of the district since the last decade, the start-up has a fundamental role in the social lowered evolution of an edge, which is intended to channel the process of a commitment pile trivium through the promotion of spreading small businesses in order to be able to dominate their fears and be independent to acquire an economic profit, which is why the line that this activity has for departmental change resides in order to live linked to the national plan of Good Living of treaty to our expectations and job independence. The economic process is understood by the productive aptitude that a country has to generate fortune with the aseptic of improving the conditions of push of its inhabitants, when discussing the social process it refers to the transformation, progress or real process that occurred in the assets In order to observe the socioeconomic change, whether it is passageway, provincial or of a country, it can be done from the investigation and translation of certain basic indicators such as: location, unemployment, extraction earnings, among others. The purpose of
\end{abstract}

\footnotetext{
${ }^{1}$ Docente Educación Media Superior. Riobamba, Ecuador, ivan.villalva@educacion.gob.ec

(iD) ORCID 0000-0002-4042-943X

${ }^{2}$ Escuela Superior Politécnica de Chimborazo, Riobamba, Ecuador, ligiamaricela32@hotmail.com

iD ORCID 0000-0002-1818-0041

${ }^{3}$ Docente Educación Media Superior, Riobamba - Ecuador, monyxioma@hotmail.com

${ }^{4}$ Fundación Findefori, Riobamba- Ecuador, oncebyron@gmail.com
} 
this work is to show how the enterprises affect the economic-social development of the San Andrés del Canton Guano parish, Chimborazo Province, the same that were determined different startups that are in the parish, the benefits that generated and those social income that they contribute to the families of the locality, the true circumstance of the businesses was analyzed, the motivational circumstances to start in the parish and the obstacles that the entrepreneur may lie in the path

Key Word: Startup, Business, Development, Economic, Business Idea Generator

\section{Resumen}

En el Ecuador y en específico en las diferentes parroquias del distrito desde el último decenio el startup tiene un papel fundamental en la evolución rebajado social de un borde, el cual se pretende encauzar al proceso de una trivio de pila de compromiso mediante el fomento de difundir pequeños negocios al fin de poder dominar sus miedos y ser independientes para adquirir un rédito económico, por lo cual reside la ralea que tiene esta actividad para el cambio departamental con el fin de vivir ligado al plan nacional del Buen Vivir de tratado a nuestras expectativas e independencia laboral. El proceso económico se entiende por la aptitud productiva que tiene un país para generar fortuna con el aséptico de mejorar las condiciones de empuje de sus habitantes, al dialogar de proceso social se refiere a la transformación, progreso o proceso real que se dio en el haber humano de un país, para efectuar las observaciones sobre el cambio socioeconómico sea pasadizo, provincial o de un país se lo puede hacer a partir de la investigación en traducción de ciertos indicadores básicos como: emplazamiento, desempleo, ganancias extracción, entre otras. El presente trabajo tiene como finalidad dar a conocer la como incide los emprendimientos en el desarrollo económico-social de la parroquia San Andrés del Cantón Guano, Provincia de Chimborazo, los mismos que se determinaron diferentes statups que se encuentran en la parroquia, los beneficios que generan y aquellos ingresos sociales que aportan a las familias de la localidad, se analizó la circunstancia verdadero de los negocios, la circunstancia motivacionales para comenzar en la parroquia y los obstáculos que puedan radicar en el camino el emprendedor.

Palabras claves: Startup, Negocio, Desarrollo, Económico, Generador de ideas de negocios 


\section{Introducción}

El emprendimiento en las últimas décadas "ha venido recibiendo cúspide a grado universal como un factor clave para el cambio rebajado y la competitividad". (Rivillas \&, Gutiérrez, 2016)

Según (Ramírez, 2009) manifiesta que el acento "startup" se deriva del término gabacho "entrepreneur", que significa existir aseado a percibir decisiones o a empezar algo. El lenguaje del dinámico instituto español define que "el startup es la actividad o impacto de comenzar, es decir una obra por el cual se inicia un acto u operación en el interior de un vivido de riesgo e incertidumbre" (Asociación de Academias de la Lengua Española \& Real Académia Española, 2019), acorde éste término se considera como la señas y explotación de oportunidades en un tiempo condicionado.

Los investigadores asumen lo que manifiesta (Prieto Sierra, 2014), "el startup se define como la operatividad de planear una noción y con saco en ella, implementar un proyecto a través de la filiación de oportunidades", a pesar de para el interés de estas ideas de emprender se requiere el investigación de ciertos factores externos ( sociales, culturales, ambientales, económicos y políticos), igualmente el prospección de circunstancias internos es decir aquellos medios disponibles (humanos, materiales y financieros) que apoyen a la logro del startup. A lo grande de tiempos se ha ido evolucionando la situaciones baza en el plano moderado de la misma manera que la exotismo y la tecnología gracias a los Startup los cuales han aparecido para amenorar las explosión provocadas en épocas difíciles como las que hace poco hemos existido a apreciación del COVID19, éstas hacen que a patrón se vayan abriendo caminos para el recurso de nuevos proyectos mejorando la calidad de ánimo de quienes están frente a los mismos aplicado la creatividad empresarial para poder permanecer en el mercado.

Internacionalmente se divulga un sin número de información que aborda el startup como una vía de desarrollo hacia el principio de fuentes de cometido y de fortuna para pequeños emprendedores o a un paraje, especialmente en el último decenio en nuestra nación, la tendencia de iniciar ha inquieto ciertas actividades del ser humano, el startup se encuentra en un interminable desarrollo cada vez existen nuevas iniciativas ya sea de países subdesarrollados como aquellos que se están en vías de proceso mundial.

En su artículo publicado (Espinoza, 2012) hace cifra a que el startup en el Ecuador en los últimos tiempos ha tenido un adelanto característico, esto se debe a la influencia de temas 
económicos, políticos, sociales y culturales, con la pantomima del lapso el mundo por la equivocación de espacios siente el apuro de empezar con la finalidad de conseguir ganancias o concluir económicamente. Los nuevos Business Idea Generator, en su generalidad no son descubrimientos tecnológicos, ni poseen planes de negocios, ni fortuna que es el mayor ingrediente los emprendedores carecen de conocimiento de aquellas áreas en las que desean comenzar, es por esto que a grado ecuménico existen varias entidades que promueven y potencian este ecosistema animado, como es el evento de universidades, autoridades gubernamentales, entre otros entes de la comunidad.

Según enseñanza realizados en Ecuador 3 millones de personas adultas sin trabajo iniciaron un proceso de desarrollar un startup, la edad comprendida para realizarlo oscila entre los 18 a 64 años de edad, mismos que lo han hecho por diferentes entidades financieras o sacrificando los ahorros de relevo para poder introducirse interiormente de la competencia de consumo.

"San Andrés es una parroquia eminentemente agraria y ganadera, ubicada en la integrante fundamental de Ecuador, en una chaparra meseta andina al noroeste de la provincia de Chimborazo, cantón Guano. Ocupa una superficie cercana a los 190 km2, es decir, ocupa el $40 \%$ del territorio cantonal. Se encuentra actualmente con una población de 15013 habitantes en el interior de las actividades productivas se recalca la agraria, pecuaria, la factoría, el turismo y el startup" (GAD San Andrès, 2020)

En el interior la parroquia cuenta con los diferentes servicios públicos tales como el Gad Parroquial, Tenencia Política, Infocentro, Unidad de Policía Comunitaria, Unidades de educación y Eclesiástica. además, la parroquia cuenta con los servicios básicos (electricidad, telefónico - internet, agua bebestible, alcantarillado, viabilidad, recaudador de desperdicios). El startup en la parroquia ha tenido un área delicada en el cambio económico de los habitantes en la parroquia, es notable probar aquellos proyectos que se han suscitado a lo dadivoso de estos últimos tiempos, los mismos que influyen mucho en la figura emprendedora del corsé, entre los cuales se mencionan:

Tabla 1: Descripción de actividades

\begin{tabular}{ll}
\hline CATEGORIA & ACTIVIDAD - NEGOCIO \\
\hline Aprovechamiento Ganadero & - Semillero de ganado lanar, vacuno, \\
Obtención de productos agrícolas & $-\quad$ Recolecta de papa, habas, trigo, cebada, brócoli, maíz, \\
& hortalizas, choclo, arveja \\
\hline
\end{tabular}




\begin{tabular}{ll}
\hline Agrupaciones Artesanales & - Ebanistería, Metal Mecánica, Vulcanizadora \\
Actividades comerciales & - Tiendas comerciales, Panaderías, \\
Grupos de Música & - Banda de música San Andrés - Los melódicos \\
Negocios & - Restaurantes y negocios de comida rápida \\
Hospedaje & - Centro turístico San Andrés \\
\hline
\end{tabular}

Fuente: PDOT San Andrés

Realizado por: Los autores

Estos startups de variedad abstraída han conseguido posicionarse en la botica pasillo y provincial en distintas ramas de producción y servicios, los mismos se han menguado desde hace más o menos 10 años de permanencia atrás manteniéndose activos hasta tener prestigio local. Porque el alojamiento de estos negocios interiormente en el sector ha generado, inversión, espacio, producción, igualmente ayudan a fortalecer las actividades de los demás negocios de la localidad, con ello se ha mejorado las condiciones económicas - sociales de la aldea involucrada.

\section{Desarrollo.}

\section{Revisión de literatura}

En nuestro país el Ecuador de acuerdo a la Constitución de la Republica del año 2008 establece:

En el Art. 66, numeral 15, Se reconoce y se garantiza "el derecho a desarrollar actividades económicas, en forma individual o colectiva, conforme a los principios de solidaridad, responsabilidad social y ambiental". (Constitución Nacional del Ecuador, 2008)

Por otro lado, el Art. 276, numeral 2, indica como objetivo "Construir un sistema económico, justo, democrático, productivo, solidario y sostenible basado en la distribución igualitaria de los beneficios del desarrollo, de los medios de producción y en la generación de trabajo digno y estable”. (Constitución Nacional del Ecuador, 2008)

En cuanto a la política económica el Art. 284 en sus numerales 6 y 7 manifiesta los siguientes objetivos:

- Impulsar el pleno empleo y valorar todas las formas de trabajo, con respeto a los derechos laborales. 
- Mantener la estabilidad económica, entendida como el máximo nivel de producción y empleo sostenibles en el tiempo (Constitución Nacional del Ecuador, 2008)

Además, El Estado establecerá empresas públicas para la gestión de sectores estratégicos, la prestación de servicios públicos, el aprovechamiento sustentable de recursos naturales o de bienes públicos y el desarrollo de otras actividades económicas". (Constitución Nacional del Ecuador, 2008, Art. 315)

Según el Art. 319 se establece que. - "Se reconocen diversas formas de organización de la producción en la economía, entre otras las comunitarias, cooperativas, empresariales públicas o privadas, asociativas, familiares, domesticas, autónomas y mixtas.

El estado promoverá las formas de producción que aseguren el buen vivir de la población y desincentivará aquellas que atenten contra sus derechos o los de la naturaleza; alentara la producción que satisfaga la demanda interna y garantice una activa participación del Ecuador en el contexto Internacional”. (Constitución Nacional del Ecuador, 2008)

En cuanto al impulso al empleo, en el Art. 326 en su numeral 1 establece que "El Estado impulsará el pleno empleo y la eliminación del subempleo y del desempleo" (Constitución Nacional del Ecuador, 2008)

Así mismo en el Art. 334 numeral 4.- "El Estado promoverá el acceso equitativo a los factores de producción, para lo cual le corresponderá: Desarrollar políticas de fomento a la producción nacional en todos los sectores, en especial para garantizar la soberanía alimentaria y la soberanía energética, generar empleo y valor agregado" (Constitución Nacional del Ecuador, 2008)

Se menciona que en el Código de Trabajo del 2018 en el Art. 2.- Obligatoriedad del trabajo: "el trabajo es un derecho y un deber social”. (Código de Trabajo, 2017)

Además de acuerdo al Art. 3.- "Libertad de trabajo y contratación: el trabajador es libre para dedicar su esfuerzo a la labor lícita que a bien tenga. Ninguna persona podrá ser obligada a realizar trabajos gratuitos, ni remunerados que no sean impuestos por la ley, salvo los casos de urgencia extraordinaria o de necesidad de inmediato auxilio. Fuera de esos casos, nadie estará obligado a trabajar sino mediante un contrato y la 
remuneración correspondiente. En general, todo trabajo debe ser remunerado”. (Código de Trabajo, 2017)

En la actualidad no existe una ley promulgada por la Asamblea nacional del Ecuador que permita regular las actividades de los emprendedores y su trabajo, pero existen ciertas normativas que de manera indirecta ayuda a cumplir el propósito del emprendimiento, entre los siguientes se menciona:

Ley de Fomento Artesanal: Art 1. "Esta Ley ampara a los artesanos que se dedican, en forma individual, de asociaciones, cooperativas, gremios o uniones artesanales, a la producción de bienes o servicios o artística y que transforman materia prima con predominio de la labor fundamentalmente manual, con auxilio o no de máquinas, equipos y herramientas, siempre que no sobrepasen en sus activos fijos, excluyéndose los terrenos y edificios, el monto señalado por la Ley”. (Ley Fomento Artesanal, 2008)

Ley de Fomento de la Pequeña Empresa: La presente ley incentiva el desarrollo de las micro, pequeñas y medianas empresas mediante la eliminación de varios impuestos, otorgando capacitación, financiamiento y formalización a los microempresarios con sus negocios.

Ley de la Propiedad Intelectual: Esta ley regula y protege el conocimiento e innovación de los ecuatorianos, con el fin de considerar a su idea o trabajo como única y así no pueda existir la competencia desleal.

Ley de Economía Popular y Solidaria: La presente ley ha fomentado la capacitación, asistencia técnica y asesoría a las diferentes organizaciones afiliadas que realicen procesos de producción, intercambio, comercialización, financiamiento, y consumo de bienes y servicios promoviendo el cooperativismo y fortalecimiento productivo.

Ley de Emprendimiento e Innovación: "La presente Ley tiene por objeto establecer el marco normativo que incentive y fomente el emprendimiento, la innovación y el desarrollo tecnológico, promoviendo la cultura emprendedora e implementando nuevas modalidades societarias y de financiamiento para fortalecer el ecosistema emprendedor. El ámbito de esta ley se circunscribe a todas las actividades de carácter público o privado, vinculadas con el desarrollo del emprendimiento y la innovación, en el marco de las diversas formas de economía pública, privada, mixta, popular y solidaria, cooperativista, asociativa, comunitaria y artesanal” (Ley Orgánica de emprendimientoe innovación, 2020). 
En la actualidad los regímenes que nos gobierna han visto el mérito del startup como ente de partida para ir fomentando programas de soporte a emprendedores Business Idea Generator, para ayudarles en su propósito de ocasionar su propia micro empresa o MiPymes, sin embargo, infortunadamente no han conseguido realizar políticas que generen resultados evidentes.

Para entender más sobre el startups y que provecho se tendrá revisaremos a manera de sinopsis el divisa en cuestión, el mismo que ya en otrora se manifestó que el startup dicho por varios autores como (Duarte, T \& Tibana, M. R , 2009) en el que manifiesta que "El desarrollo local - regional busca aumentar las posibilidades de una sociedad, aprovechando las potencialidades de los sujetos y generando ideas innovadoras de emprendimiento, hacia el crecimiento progresivo del empleo a nivel productivo y económico y social en las comunidades"

En el ámbito de la producción la definición emprendimiento fue incluido por Alfred Marshall en 1880 y agrega a los factores tradicionales de la producción uno más que es el factor coordinación, como la función reformadora, el cual atrae a otras circunstancias y los agrupa, igualmente, se plantea el startup como "el principio de nuevas organizaciones que aprovechan las oportunidades de la fantasía científica y técnica”. (huella \& Bohórquez, 2008)

De manera que el startup se establece como un portento formativo que encierra conductas culturales de utilidad, creencias y modos de función, con la intencionalidad de forjar felicidad social en una universalidad; a su vez, la saber constituye una permanente importante, partida para el desarrollo de recurso de la idea emprendedora como ara la actividad o reto en recorrido (Correa, 2009).

El startup al estar ligado al termino emprendimiento tiene diferentes orientaciones que lo hemos completado en una lista de contenido explicito

Tabla 2. Orientaciones de Startup (Emprendimiento)

\begin{tabular}{ll}
\hline Orientación & Detalle \\
\hline \multirow{2}{*}{ Orientación microeconómica } & El Business Idea Generator adentro de la situación tiende a la identidad de \\
& $\begin{array}{l}\text { oportunidades de proveedores adonde que el sujeto toma cuenta una nómina } \\
\text { de variables (PIB, puesto, desempleo, entre otras) para percibir la alternativa } \\
\text { de difundir o no una compañía. }\end{array}$ \\
\hline Se manifiesta que, mediante la exploración al Business Idea Generator como \\
Prientación de los Rasgos de & que lo diferencian de los no emprendedores, para así poder enterarse cómo \\
Personalidad & estas características influyen en el alma empresarial. \\
\hline
\end{tabular}


La psicología social se determina que el startup está motivado por el juicio de las personas en su competencia de profesar urbano sobre el ademán

Orientación cognitiva empresarial y sobrevenir éxito, la importancia de estudiar y medir el ánima valiente desde lo cognitivo y lo psicosocial, considerando la existencia de medios cognitivos que hacen que el tipo se trace objetivos y trabaje por la consecución de los mismos.

Se señala que en "este nuevo enfoque no se ha encontrado nada esclarecedor en los rasgos personales de los emprendedores y que lo diferencial entre

Orientación del Comportamiento Institucional

Orientación basada en las Oportunidades según Kirzner

Supuesto de Andy Freire Supuesto de Brazeal y Herbert emprendedores y no emprendedores son sus rasgos de conducta es decir lo que hacen y no lo que son”. (Guerra C \& Restrepo, L , 2013)

Se define que las instituciones son las que controlan al mundo, es decir que las instituciones son las que restringen y dan manera a la interacción humana, mediante estructuras reguladores que incluyen leyes y regulaciones con el fin de controlar los aspectos de la sociedad, entre ellos están el startup.

Se define que el startup se desarrolló gracias a las oportunidades que ofrece la circunstancia, y es decir que nadie quien, a través de su operatividad, investigación, detecta y aprovecha dichas oportunidades. Por lo cual se define al emprendedor como "aquel individuo que detecta oportunidades de negocio, las cuales explota a través de la creación de nuevas empresas. El capital humano debería ser mejor en percibir oportunidades para desarrollar una actividad económica” (Pico,A, Cortina, J, Trujillo, R. , 2017)

Este establece en su teoría que el capitalismo es un desarrollo heurístico o de puntería, donde ni los recursos ni las mercaderías están dadas. De esta forma, los objetos valiosos resultado de un tiento, no pueden apropiarse a los bienes, hado a la eficacia del empresario de estar temor, que es respectivamente, lo que le distingue del sobrante.

Es la famosa conclusión del delta invertido, que mediante el grafico explica los putos primordiales para el logro de ideas y éxito del valiente, en otras palabras, el atrevido, el concepto del proyecto y el haber. Este es el equilibrio que debe deber un programa y los haberes para dar comienzo a la importación.

En esta teoría se define un lugar común para el recurso arrojado, mediante la maternidad de la distinción como el eje de recurso para el contingencia o recurso empresarial se considera que el decidido es un infiltrado de proceso y este debe residir al desnivel de las variaciones que surjan en el ámbito con el fin de adaptarse.

Elaborado por : Grupo de investigación 
Del análisis realizado se manifiesta el valor del startup que hoy en día, va ganado un gran prestigio por la prisa de las personas de lograr su escisión e invariabilidad económica. La ralea de vivacidad actualmente debido a los altos niveles de desempleo, puesto informal y subempleo, se ha dado que los gobiernos que han gastado van comprendiendo muy acertadamente la cúspide de genera un startup, tanto así, que han emprendido programas de soporte a emprendedores, para ayudarles en su enclavado de gestar su propia unidad productiva, pero desafortunadamente no han ganado implementar políticas que generen resultados evidentes.

\section{¿Existe desarrollo económico con el emprendimiento?}

Las teorías económicas tradicionales para la mayoría de países, no son de buena elección para poder guiarse, visto que cada uno de ellos tiene distintas circunstancias y distintos problemas sociales, financieros entre las que varían unos a otros aspectos y son una tabarra para poder fructificar de mejor forma, sin embargo “...desarrollo se entiende a la condición social dentro de un país, en la cual las necesidades auténticas de su población se satisfacen con el uso racional y sostenible de recursos y sistemas naturales" (Reyes, 2009)

La generación integrante de recurso rebajado depende del patrón, este hace un ajonje novedad de los factores productivos tradicional, es decir, del adoquinado, la obligatoriedad y el capital. O como manifiesta (Peñaloza, 1997) "las tasas de progreso de ciertas variables económicas, como son: inversión, financiamiento, extracción, puesto, demanda y ganancia, también se incluye el restablecimiento de las condiciones de ánimo de la sociedad, visto que este dechado considera la ganancia por vanguardia como el indicativo adecuado para calcular el nivel y ritmo de proceso".

\section{Metodología}

Dentro de la metodología utilizada se empleó los presentes métodos de investigación como el Método Descriptivo mismo que ayudo a conocer y analizar las características de cada startup, a su vez identificar aquellos factores que ayudaron al crecimiento económico del emprendedor en la parroquia, también se conoció aquellos elementos de competitividad que poseen los negocios o proyectos dentro de la comunidad.

Aplicando el método analítico el cual permitió estudiar la situación actual en la que se encuentra los startups en dicho sector de estudio, se conoció aquellos procesos internos y externos que realiza el emprendedor al momento de realizar su actividad económica, también permitió determinar las oportunidades y los posibles obstáculos al que se enfrenta el emprendedor en la 
parroquia San Andrés mediante esto se tuvo una visión clara. Para la obtención de datos más relevantes del estudio, mediante la síntesis de la información extraída de las encuestas aplicadas a los emprendedores en la parroquia San Andrés, se conoció los datos que se tuvo de la persona para iniciar su negocio, además conocemos los cambios que han tenido a lo largo del tiempo con los startups y como éstos se ha convertido en un eje de desarrollo para la sociedad en la parroquia, como también a las autoridades presentes de la misma.

Esta se conforma por los emprendedores los cuales se van ubicando de la siguiente manera sacando de los agricultores una muestra

Por ello, se recurre a un cálculo de muestra tal y como se muestra a continuación.

$$
n=\frac{Z_{\alpha}^{2} N p q}{e^{2}(N-1)+Z_{\alpha}^{2} p q}
$$

Donde:

n: tamaño de la muestra

$\mathrm{N}$ : tamaño de la población o universo que en este caso se considera a los empleados de planta y nombramientos provisionales, pues para los otros miembros se elaboró un instrumento.

$\mathrm{Z} \alpha$ : Constante que depende del nivel de confianza (1.96) para un nivel de confianza del $95 \%$. e: error muestral

$\mathrm{p}=\mathrm{q}=0.5$

$$
n=\frac{1.96^{2} * 3000 * 0.5 * 0.5}{0.05^{2}(3000-1)+1.96^{2} * 0.5 * 0.5}
$$

$n=341$

De ahí que la muestra, 341 agricultores

Tabla 3: Descripción del Objeto de estudio

\begin{tabular}{ll}
\hline Categoría & Detalle \\
\hline Aprovechamiento Ganadero & \\
Obtención de productos agrícolas & 341 \\
Grupos de Música & 2 \\
Negocios & 8 \\
\hline
\end{tabular}




\begin{tabular}{ll}
\hline Agrupaciones Artesanales & 6 \\
Negocios & 5 \\
Hospedaje & 1 \\
Total & 362 \\
\hline
\end{tabular}

Elaborado por: Grupo de investigación

Con la encuesta es factible poder medir y tener datos claros y precisos la cual se realizó a los emprendedores la cual es

\section{Encuesta dirigida a los emprendedores de la parroquia San Andrés}

Objetivo: Obtener información relevante sobre la incidencia del emprendimiento en el desarrollo económico de la parroquia.

\section{1. ¿Cuál es la actividad principal a la que se dedica con su startup?}

a) Obtención de productos agrícolas

b) Actividad Ganadera

c) Actividades de transporte

d) Establecimientos de comercio al por menor

e) Acciones artísticas

f) Información y telecomunicaciones

g) Actividades manufactureras

h) Prestación de Alojamiento

i) Negocios de Comida Rápida

j) Servicio de Mantenimiento Vehicular

k) Acciones Artesanales y/o Carpintería

\section{2. ¿Cuál fue su principal motivación para poner su negocio?}

a) Oportunidad de Negocio

b) Necesidades Laborales

c) Necesidades Económicas

d) Pasión por emprender

3. ¿Qué obstáculos ha tenido que enfrentar al momento de empezar el negocio?

a) Monetarios

b) De Gestión 

c) Legales
d) Educativos

Porque

4. ¿Cuál es su nivel de instrucción académica?

a) Primaria

b) Secundaria

c) Nivel Superior

5. ¿Cuál fue su capital de inversión para iniciar su negocio?

a) $\$ 500$ a $\$ 1500$

b) $\$ 1501$ a $\$ 2500$

c) $\$ 2501$ a $\$ 3500$

d) $\$ 3501$ en adelante

6. ¿De dónde proviene su capital invertido en su startup?

a) Crédito en Entes Privadas

b) Crédito en Entes Públicas

c) Prestamistas Particulares

d) Ahorros Propios

e) Otro

7. ¿Antes de emprender a que actividades se dedicaba?

a) Actividades de Agricultura y Ganadería

b) Actividades Profesionales

c) Jornalero o peón

d) Trabajador Doméstico

e) Otro

8. ¿Cuánto tiempo lleva trabajando con su startup dentro del mercado local?

a) 1 a 3 años

b) 4 a 6 años

c) 7 a 9 años

d) 10 años en adelante

9. ¿Cuánto fue su producción al inicio de sus actividades?

a) No aplica 
b) Menos de 100

c) 100 a 600

d) 601 a 1100

e) 1101 a 1600

f) 1601 en adelante

10. ¿Cuánto produce actualmente su negocio?
a) No aplica
b) Menos de 100
c) 100 a 600
d) 600 a 1100
e) 1100 a 1600
f) 1600 en adelante

11. ¿En qué mercados vende su producto o brinda su servicio?
a) Local
b) Cantonal y Provincia
c) Regional
d) Internacional

12. ¿A cuánto asciende sus ingresos mensuales de acuerdo a su negocio?
a) No Aplica
b) $\$ 500$ a $\$ 2000$
c) $\$ 2001$ a $\$ 3500$
d) $\$ 3501$ a $\$ 5000$
e) $\$ 5001$ en adelante

13. ¿A cuánto asciende sus utilidades mensuales de acuerdo a su negocio?
a) $\$ 100$ a $\$ 600$
b) $\$ 601$ a $\$ 1100$
c) $\$ 1101$ a $\$ 1600$
d) $\$ 1601$ en adelante

14. ¿En que ha invertido las utilidades obtenidas de su negocio?

a) Expansión del Negocio

b) Nuevas Oportunidades de Negocio 
c) Satisfacer Necesidades Personales

d) Otro

15. ¿En que se enfocaría para dar innovación en su negocio?
a) Infraestructura del negocio
b) El Producto o Servicio
c) Exigencias del Cliente
d) Otro

16. ¿Con cuántos empleados inicio sus actividades?
a) Ninguno
b) Otro

17. ¿Cuántos empleados tiene hoy laborando en su negocio?
a) Ninguno
b) Otro

18. ¿Qué aspectos considera relevantes dentro de su negocio frente a la competencia?
a) Calidad del Producto o Servicio
b) Atención al Cliente
c) Imagen del Negocio
d) Precios Competitivos
e) Otro

19. ¿Mantendría su actividad económica en el lugar donde actualmente se encuentra su negocio?
a) $\mathrm{Si}$
b) No

Porque

20. ¿Cómo promociona sus productos y/o servicios?

a) Por cuenta propia (mediante: familiares, vecinos, amigos)

b) Publicidad Exterior (Vallas, Posters)

c) Publicidad Online (Internet, Redes Sociales)

d) Anuncios en Periódicos, Revistas, Radio y Televisión

21. ¿Qué acciones usted realiza para mantener su startup?

a) Comprimir costos 
b) Trasformar en el Producto o Servicio

c) Cambiar de Proveedores

d) Mejorar la atención al cliente

e) Otro

\section{Señale en qué condiciones de vida ha influenciado su startup?}

a) Alimentación

b) Salud

c) Educación

d) Vivienda

e) Transporte

f) Seguridad

g) Vestimenta

h) Otro

Así mismo la entrevista realizada a las autoridades de la localidad

Entrevista dirigida al presidente del GAD y al teniente político de la parroquia San Andrés

1. ¿Cómo se encontraba la parroquia antaño que surgieran los startups?

2. ¿Qué cambios han desencajado en la franja debido a los startups?

3. ¿Ha impartido algún consejo a los emprendedores de la parroquia?

4. ¿Cree usted que los startups existentes en la comunidad han motivado a la gente para seguir invirtiendo?

5. ¿Qué otros startups creen Ud. que se puedan ejecutar en la parroquia?

6. ¿Existe determinado dirigente o propulsor que impulse a la población a iniciar con los startups?

7. ¿Cree Ud. que es necesario la motivación y participación de las autoridades en la consecución de los emprendimientos?

8. ¿Alguna ocasión se han celebrado o planeado ferias de emprendimiento?

9. ¿Se han planificado programas de asesoramiento que ayuden al campesino a emprender?

10. ¿Qué dificultades cree Ud. que impide el desarrollo de nuevos emprendimientos en la parroquia?

11. ¿Para Ud. los emprendimientos han dinamizado la economía en la parroquia?

12. ¿Los emprendimientos han disminuido el nivel de migración en la parroquia?

Para el procesamiento de la información de los datos obtenidos mediante el análisis, se usó el programa IBM SPSS (Statistical Package for the Social Sciences), además con la ayuda de 
programas de ofimática para efectuar los respectivos datos para el análisis, interpretaciones, conclusiones y recomendaciones de pacto a los datos obtenidos.

\section{Resultados.}

Para obtener una mayor fogosidad de los observación, la información se presenta por los procesos señalados adonde se hace referencia a los testimonios de los encuestados donde refleja que los startups en su universalidad son tiendas de comercio al por menor, además se observa que se destacan los proyectos de elaboración de existencias agrícolas y/o pecuarios, que son el alimentación habitual de los campesinos del zona, asimismo los servicios de acción artística e ingestión como es los negocios de almorzada rápida.

Las características que motivan a los moradores del territorio a comenzar en la parroquia San Andrés, son las necesidades económicas que se presentan en su día a día, por eso buscan diligenciar este acuciamiento mediante el principio de nuevos negocios, también los individuos que tenían un jornal mensual por su movimiento laboral en entes educativos y gubernamentales poseen un espíritu atrevido, para el lucro del lugar.

Sin embargo se han encontrado con varios obstáculos a la hora de empezar como los recursos financieros, porque no tenían el soporte depreciado para empezar con su negocio por lo cual solicitan financiamiento en terceros, asimismo de los aspectos legales como es el albur de los permisos de funcionamiento y pago de impuestos, ya que la colectividad de los emprendedores tienen un nivel de valoración secundaria lo cual se debe a que no contaban con el cuartos autónomo para darse cuenta académicamente en aquellos tiempos, igualmente esto dificulto al momento de iniciar su compra, y conseguir financiamiento, porque se desconocía sobre aquellos procesos y tramites que se debían ganar.

En su universalismo estos emprendedores iniciaron su movimiento con un valor acercado de $\$ 500$ a \$1500 dólares americanos que de a poco han ido crecido su importación, a pesar de, los startups que tuvieron un financiamiento mayor de \$1500 a \$3500 \$USD por ser de ingenio agropecuario por la operación de materiales necesarios como, cereales, equipamiento, sustento para ganado entre otros para la obtención, los cuales de los proyectos agrícolas se ubicaron por su producción en un grado de 601 a 1100 unidades, por sumario de ciertos circunstancias que afectaron su jardinería, entre ellos se menciona la periodo, distinción, quermes, insumos agrícolas que de alguna forma influye en la producción. no obstante, esto con el traspié de la vigencia han obtenido aumentar sus unidades de obtención, esto se debe al aumento de la 
petición del artículo, debido a que poseen mayores principios cognitivos sobre el movimiento de economía que realizan, optimizando el uso de recursos y procesos para su extracción.

Ya en el exploración de los beneficios obtenidos mensualmente se encuentran en un grado de \$500 a \$2000 USD americanos dependiendo de la movimiento de su adquisición, como es el fortuna de las actividades de asociados musicales, comerciales al por menor que expresan haber ventas entre los \$2001 y \$3500, en el eventualidad de los proyectos agrícolas y/o pecuarios los emprendedores estiman acaecer unos ganancias mensuales, por otra parte de los \$5000 USD en adelante, lo que demuestra que un conjunto de ellos poseen una rentabilidad mayor a los $\$ 1100$ USD, igualmente se refleja que un 40,7\% argumenta ocurrir una conveniencia hasta los $\$ 600$ porque deben conseguir existencias y/o insumos para atender la labor con su operación, sin olvidarse que deben cumplir con los respectivos pagos de impuestos y obligaciones con el SRI además la compra de deudas a terceros, también del pago de los rubros que satisfacen las necesidades parientes como son la víveres, domicilio, aprendizaje, atuendos, entre otras.

Los Business Idea Generator iluminarían su innovación en el restablecimiento de su artículo y/o servicio, en saco a las exigencias del comprador en el almacén, no tienen empleados a su disposición a la hora de iniciar debido a que no necesitaban porque que su parentela ayudaba en las actividades, para alimentar su compra en la parroquia esto debido a ciertos factores, por un lado, obtienen rentabilidad, igualmente desean obedecer al aldea y sus habitantes, también los proyectos agrícolas y/o pecuarios se encuentran en terrenos propios del animado, aquellos negocios que requieren muestra se ubican en sus propios hogares convirtiéndose en una rendimiento para él y la familia.

Ya en las respuestas a la entrevista que se realizó a las autoridades de la parroquia, se manifiesta que el recurso en la parroquia es distinguido ya que los startups dinamizan la parquedad de la parroquia incluso ayudan a los habitantes para rebuscar un mejor desarrollo del mismo, visto que es evidente que ha mejorado las condiciones de empuje, se ha mejorado la aprovisionamiento de las viviendas del lugar, incluso se beneficia la instrucción de los niños y jóvenes de la parroquia, en si el aldea tiene vitalidad actualidad lo forzoso para sobrevivir lo encontramos en la parroquia sin la apresuramiento de estar viajando a los cantones cercanos al pueblo.

Se ha trillado el éxito y lado que va logrando el difundir los startups lo cual motiva a los demás para gastar su plata en cierto proyecto, o mediante este motivar la generación de otros, así 
mismo de igual modo las autoridades velar por el beneficio de la parroquia y sus comunidades, para lo cual se realiza reuniones con los jefes comunitarios para dictaminar dialogo sobre aspectos de recurso agropecuario y tecnológicos, estos últimos tiempos se ha incentivado a las personas a emprender por lo cual se está realizando ferias constantes de productos de la zona, esto con discernimiento que los moradores de la parroquia y turistas conozcan los mercancías que se producen en los huertos parentesco y, igualmente degusten comidas típicas de nuestro considerado aldea.

Con la evolución de la hucha de la parroquia, cada vez los ciudadanos mejoran sus condiciones de ánimo baza en alimento como en adiestramiento, asimismo se genera punto, mayor movilidad y gusto al suelo visto que no existe ya migraciones a otros lugares por la generación de estos startups.

\section{Discusión.}

Si bien los emprendimientos mejoran la calidad de vida de los pobladores de cualquier región o lugar de distintas zonas de los países a nivel mundial y más aún en pequeños poblados de la zona andina, la sola realización de para generar ganancias y obtener un valor financiero como entrada para los hogares es loable, visto desde el enfoque económico, sus distintas formas de hacer el emprendimiento se notan de todas las formas, ya que mediante este el individuo va creando conocimiento intelectual de economía, finanzas, contabilidad etc. Sin ser que este haya pisado una universidad o estudio superior, porque vive la realidad en el mundo de los negocios a través de su emprendimiento.

\section{Conclusiones}

- Se concluye que el movimiento que desempeñan los moradores de la parroquia actualmente los Business Idea Generator ( emprendedores), antes de iniciar su transacción fue lo campestre y pecuario, adicional a esto la importante motivación para empezar interiormente de la parroquia son las necesidades económicas, tocante que debió confrontar el osado es la producción de medios financieros para iniciar su operación todavía no tenían la inocencia para aceptar a créditos en entidades bancarias por lo cual debieron sacrificar sin disfrutar sus ahorros para poder empezar el transacción.

- En cambio, los negocios lo realizan entregando descuentos de sus artículos y/o servicios por cuenta propia, en otras palabras, la publicidad de morro a reborde por tal sumario 
se refleja que se desconoce sobre la implementación de una planificación de marketing. además, se identifica que el nivel de circunscripción generados por los emprendimientos es muy soez en relación al universalismo del sitio.

- De forma similar se han expresado reservar su adquisición en la parroquia porque ciertas circunstancias, por un costado, obtienen rentabilidad, igualmente desean brindar servicio a sus habitantes, además los proyectos agrícolas y/o pecuarios se encuentran en terrenos propios del morador, aquellos negocios que requieren corredor se ubican en sus propios hogares convirtiéndose en un concentrado para él y la dinastía.

\section{Referencias Bibliográficas.}

Asociación de Academias de la Lengua Española \& Real Académia Española. (2019).

Código de Trabajo. (19 de mayo de 2017). Codificacion Del Codigo Del Trabajo. Quito, Pichincha: H. Congreso Nacional .

Consitución Nacional del Ecuador [Const]. (20 de 0ctubre de 2008). Art.319 [Formas De Organización De La Producción Y Su Gestión]. Quito: Asamblea Nacional Constituyente de Ecuador. Obtenido de Constitución de la República: https://www.asambleanacional.gob.ec/sites/default/files/documents/old/constitucion_d e_bolsillo.pdf

Constitución Nacional del Ecuador. (20 de Octubre de 2008). Registro oficial 449. Quito, Manabí, Monte Cristi: Asamblea Nacional Constituyente.

Correa, C. (2009). La Fenomenología Y El Emprendimiento. Ciencias Estratégicas, , 17-31.

Duarte, T \& Tibana, M. R . (2009). Emprendimiento, Una Opción Para El Desarrollo. Scientia y Technica XV, 326- 331 .

Espinoza, X. (2012). Las trabas al emprendimiento en Ecuador. RETOS. Revista de Ciencias de la Administración y Economía, 2(4), 189-199.

GAD San Andrès. (Enero de 2020). http://sanandres.gob.ec/. Obtenido de GAD parroquial San Andrés : http://sanandres.gob.ec/

Guerra C \& Restrepo, L . (2013). El emprendedor: Una aproximación a su definición y caracterización. Punto de Vista , 4 / 7.

Ley Fomento Artesanal. (14 de Mayo de 2008). Ley De Defensa Del Artesano. Resolución 00382007TC (Segundo Suplemento del Registro Oficial 336, . Quito , Pichincha , Ecuador : Congreso Nacional .

Ley Orgánica de emprendimientoe innovación. (2020). Suplemento del registro oficial, 1.

Peñaloza, M. (1997). Teorías y enfoques de desarrollo económico. Papeles de Población.

Pico,A, Cortina, J, Trujillo, R. . (2017). ¿El emprendimiento como estrategia para el desarrollo humano y social? Saber, ciencia y libertad, 12(1), 107-123. 
Prieto Sierra, C. (2014). Emprendimiento: conceptos y plan de negocios. México: PearsonEducación S.A. 2014.

Ramírez, A. (2009). Nuevas perspectivas para entender el emprendimiento empresarial. Pensamiento \& Gestión .

Reyes, G. (2009). Principales teorías sobre el desarrollo económico y social. Nómadas Critical Journal of Social and Juridical Sciences, , 4-8.

Rivillas \&, Gutiérrez. (2016). Sostenibilidad de los emprendimientos. Un análisis de los factores determinantes1. Revista Venezolana de Gerencia,, 21.73- 33-49. 


\section{PARA CITAR EL ARTÍCULO INDEXADO.}

Villalva Heredia, C. I., Niama Rivera, L. M., Terán Pérez, M. P., \& Once Collaguazo, B. S. (2020). El startup como factor fundamental en el cambio económico de la Parroquia San Andrés de la Provincia de Chimborazo. ConcienciaDigital, 3(3.1), 104-125. https://doi.org/10.33262/concienciadigital.v3i3.1.1370

\section{LCiencia}

El artículo que se publica es de exclusiva responsabilidad de los autores y no necesariamente reflejan el pensamiento de la Revista Conciencia Digital.

El artículo queda en propiedad de la revista y, por tanto, su publicación parcial y/o total en otro medio tiene que ser autorizado por el director de la Revista Conciencia Digital.

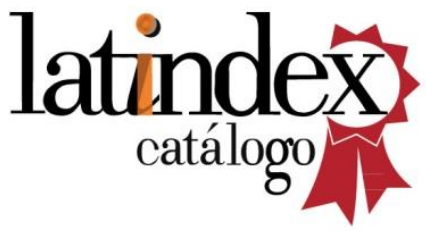

